\title{
"Unwell while Aboriginal": iatrogenesis in Australian medical education and clinical case management
}

This article was published in the following Dove Press journal:

Advances in Medical Education and Practice

27 May 2016

Number of times this article has been viewed

\author{
Shaun C Ewen' \\ David Hollinsworth ${ }^{2}$ \\ 'Melbourne Poche Centre for \\ Indigenous Health, Faculty of \\ Medicine, Dentistry and Health \\ Sciences, The University of Melbourne, \\ Melbourne, VIC, ${ }^{2}$ Indigenous Studies, \\ Faculty of Arts, Business and Law, \\ University of the Sunshine Coast, \\ Sippy Downs, QLD, Australia
}

Introduction: Attention to Aboriginal health has become mandatory in Australian medical education. In parallel, clinical management has increasingly used Aboriginality as an identifier in both decision making and reporting of morbidity and mortality. This focus is applauded in light of the gross inequalities in health outcomes between indigenous people and other Australians. Methods: A purposive survey of relevant Australian and international literature was conducted to map the current state of play and identify concerns with efforts to teach cultural competence with Aboriginal people in medical schools and to provide "culturally appropriate" clinical care. The authors critically analyzed this literature in light of their experiences in teaching Aboriginal studies over six decades in many universities to generate examples of iatrogenic effects and possible responses.

Results and discussion: Understanding how to most effectively embed Aboriginal content and perspectives in curriculum and how to best teach and assess these remains contested. This review canvasses these debates, arguing that well-intentioned efforts in medical education and clinical management can have iatrogenic impacts. Given the long history of racialization of Aboriginal people in Australian medicine and the relatively low levels of routine contact with Aboriginal people among students and clinicians, the review urges caution in compounding these iatrogenic effects and proposes strategies to combat or reduce them.

Conclusion: Long overdue efforts to recognize gaps and inadequacies in medical education about Aboriginal people and their health and to provide equitable health services and improved health outcomes are needed and welcome. Such efforts need to be critically examined and rigorously evaluated to avoid the reproduction of pathologizing stereotypes and reductionist explanations for persistent poor outcomes for Aboriginal people.

Keywords: indigenous health, minority health, implicit bias, equity

\section{Introduction}

Iatrogenesis is broadly defined as the side effects (mostly unwanted or undesirable) of medical interventions and would include a scar from surgery, to the more complicated side effects of complex drug interactions. This article adopts the approach that iatrogenic effects can be broadly and "distally" defined to illuminate the diverse effects of racialized representation in various medical settings.

The health of Aboriginal Australians is significantly worse than that of other Australians despite considerable policy and funding attention in recent decades. ${ }^{1}$ This article argues that well-intentioned approaches in the health system to address Australian Aboriginal health have had iatrogenic effects. Canvassing medical education and clinical care, this review
Correspondence: Shaun C Ewen Melbourne Poche Centre for Indigenous Health, Faculty of Medicine, Dentistry and Health Sciences, The University of Melbourne, Level 2, 16I Barry Street, Carlton 3053, Melbourne, VIC, Australia Email shaun.ewen@unimelb.edu.au 
outlines some of the unforeseen consequences and urges health professionals and academics to critically reflect on, record, and combat the iatrogenic effects of these initiatives.

\section{Methods}

A purposive survey ${ }^{2,3}$ of relevant Australian and international literature was conducted to map the current state of play and identify concerns with efforts to teach cultural competence with Aboriginal people in medical schools and to provide "culturally appropriate" clinical care. There have been previous systematic reviews of cultural competence, ${ }^{4,5}$ and a purposive review was deemed more appropriate to target the smaller literature of specific reference to the issue of iatrogenesis. The authors collaborated to critically review key aspects of the relevant literature based on their experiences of teaching Aboriginal studies to health professionals, including doctors, nurses, and allied health professionals (occupational therapists, radiologists, physiotherapists, and health promotion workers). Collectively, this experience totals more than six decades in several universities, spanning the earliest efforts to introduce indigenous cultural competence till today, to generate examples of iatrogenic effects and possible responses.

\section{Results and discussion}

The discussion section is divided into two parts. First, we review iatrogenesis in teaching and learning of indigenous health and possible responses to this, drawing upon the purposive review of the literature. Second, we turn our attention to iatrogenesis in hospital and clinical management and responses within that context.

\section{latrogenesis in teaching and learning}

Aboriginal health has become increasingly included as an accreditation requirement across the health professions. The most notable and comprehensive approach to the inclusion of Aboriginal health in the accreditation standards and related activity can be seen in medical education. ${ }^{6,7}$ Much of the curriculum development response has been to include Aboriginal examples to highlight particular diseases for which the Aboriginal population carries a specific high burden, such as diabetes. This approach was driven in part by the widespread use of problem-based learning (PBL) in medical education, despite serious concerns for its effectiveness in strengthening students' knowledge base and maximizing clinical performance. ${ }^{8,9}$ Treloar et al ${ }^{10}$ question the effectiveness of PBL for nonmainstream Australian medical students, while other studies document the variability of PBL tutors' confidence in handling cases from racialized groups. ${ }^{11,12}$
Aboriginal PBL cases typically pathologize the Aboriginal person (patient) independent of the disease or body system problem of the week to be solved. Given the hegemony of a scientific, body systems approach, the "Aboriginal case" was logically secondary to the associated burden of disease profile (refer Kai et $\mathrm{al}^{11}$ for UK examples of racialization of PBL cases). Given Aboriginal people are three to four times more likely to have a diagnosis of diabetes, or heart disease, or several times more likely to smoke, ${ }^{1}$ they become prime candidates to become the sociocultural clothes to dress up the skeleton of the diagnosis or problem. Thus, throughout the educational journey to medical practice, Aboriginality is constructed as the problem and pathologized. ${ }^{13}$ This problematic representation has a long history in Australia ${ }^{14-16}$ and is amplified for medical students who rarely encounter alternative representations in either their medical education or the wider profession.

Given the content of educational material/pedagogy just described, it is highly likely that across the learning arc of an entry to practice medicine professional degree, many graduates will only have "experienced" Aboriginality as a disease and the presumption that the concomitant social determinants of education, housing, access to health services apply. ${ }^{17}$ This misrepresentation of Aboriginality as pathology encourages the acceptance of high levels of morbidity and misdirects clinicians away from specific contextual factors. Given the very low numbers (real and relative) of Aboriginal health educators training the health workforce, the examples of Aboriginal people that students experience will overwhelmingly be as "sick" inclusions in the curriculum, or less often, as patients. Rarely will the clinician or professor be Aboriginal. A parallel underrepresentation has been found for African American medical educators. ${ }^{18}$ This phenomenon was raised with one of the authors of this article by his Aboriginal students in a medical course, who challenged the curricula, indicating "I don't see myself in any of the curriculum being presented". This critique echoes the sector-wide problem for Aboriginal participation invoked as “can't be what you can't see". ${ }^{19}$

\section{Responses}

There are several responses to countering the iatrogenic effect of an overwhelming and essentialized burden of disease approach to curriculum. The first is to consider strength-based approaches to curriculum representation. An example of this would be the inclusion of Aboriginal people in the curriculum, where their identity is separate from their disease. This can be done through several ways, employing formal, informal, and hidden curriculum examples. 
The formal curriculum example, in which the students learn in the structured, planned, and documented curriculum, could include representations of doctors being Aboriginal rather than just unwell patients. Another example could be the inclusion of Aboriginal patients in cases that do not explicitly link a burden of disease with a sociocultural identity and that challenge stereotypes. This could include a young Aboriginal patient having a skin cancer scare, due to sun exposure from surfing, and as a university student and an Aboriginal patient as the paper case in preparation for a gerontology discussion. Both these cases challenge stereotypes of Aboriginality, one being young, active, and at university and the other being of an age where gerontology is warranted (as opposed to death at an early age). All Aboriginal content should stress diversity and the intersectionality of race with other aspects of identity, including sex, age, education, sexuality, dis/ ability, and geographical location. ${ }^{20}$ This important learning will be difficult for many students (and staff) who lack direct experience with Aboriginal people as was found for Ontario medical students despite quality curriculum specifically highlighting diversity. ${ }^{21}$ Besides formal curriculum around health disparities for minority populations, medical education needs specific content on various forms of racism and their impact on health, ${ }^{22,23}$ and on unrecognized white privilege and stereotyping within health services. ${ }^{24-28}$

The informal curriculum consists of many interpersonal interactions between people who make up the medical education program, including students, teachers, clinicians, and patients. In Australia, non-Aboriginal Australians are overrepresented in the health workforce. The implications for this on the informal curriculum have been described previously. ${ }^{29}$ An additional approach is to actively work to support and promote Aboriginal academics as senior members of teaching and clinical staff. ${ }^{12,14}$

Hafferty ${ }^{30}$ directs us to policy development, evaluation, resource allocation, and institutional slang or nomenclature as key indicators of the hidden curriculum. Studies in American medical schools found that formal, informal, and hidden curricula should be explicitly addressed to raise the consciousness of instructors and students about implicit racial bias..$^{31}$ One form of institutional slang or nomenclature is the institutional environment and the naming of building and lecture theatres. ${ }^{32,33} \mathrm{~A}$ medical school may wish to name, or rename, buildings and lecture theatres, which are representatives of the values appropriate for the 21 st century, rather than continue to implicitly reify names, which may reflect now debunked, racist, and marginalizing world views. This suggests that a nuanced approach, which strives for balance, underpinned by reflexivity may be taken when considering the environment in which medical students are trained. Again, the iatrogenic effect of teaching in buildings named after eugenicists, for example, is not so much the stench of a eugenics approach but rather the lingering impact of the keloid scar it leaves, as it continually reminds of the historical "place" of the Aborigine.

\section{latrogenesis in hospital and clinical management}

There are many good reasons to collect demographic data for hospital or other health centers, admissions, and occasions of service. Indeed, it is considered mandatory to ask a range of demographic questions upon admission, ranging from age, sex, postcode, and ethnicity. The recording of Aboriginal ethnicity is considered as an important element in collecting data to help determine program and policy priorities (but note the counter argument in Canada). ${ }^{34,35}$ Many good initiatives have flowed from this practice, including allocation of resources to support Aboriginal Hospital Liaison Officers and the development of Aboriginal-specific clinics.

However, we also know more about the impact of a clinician's implicit bias on their decision making. ${ }^{36-39}$ There is a significant research documenting iatrogenic effects on the patient whose hospital or clinical records identify her as Aboriginal, either by use of a tick a box or more visually by the placing of an Aboriginal flag on the records ${ }^{40-44}$ Implicit bias and a range of unhelpful stereotypical assumptions may be triggered when the clinician or administrator see a patient record displaying an Aboriginal flag. This may include assumptions about their socioeconomic status, their worthiness to receive treatment, and the extent to which they might be compliant to any treatment or management plan, all of which may affect the clinician's decision making. ${ }^{45}$ Critical reflection offers an improved decision making especially when the clinician is uncertain or with complex conditions as is frequently the situation in dealing with Aboriginal patients. ${ }^{46}$ Critical analysis of clinicians' (in)actions needs to be complemented by more systemic analysis of hospital protocols and procedures to reveal iatrogenic impacts at the structural level. Examples include discharge against medical advice $^{47}$ and poor or lack of communication to the Aboriginal patient's family physician or community clinic. ${ }^{48}$

\section{Responses}

If the implicit and unconscious bias triggers a range of unhelpful responses for the clinician (and thus, for the patient), what parallel activities could a health service 
provide to help counter this implicit bias? A recent article ${ }^{31}$ demonstrates that exposure to implicit bias testing, used as a training tool, reduced implicit racial bias among medical students in the USA. Research suggests "that educators must be deliberate and skilled in their facilitation of reflection and discussion about UB [unconscious bias] and its relevance to clinical practice". ${ }^{38}$ Such explicit instruction and selfassessment for implicit bias could be extended to hospital orientation procedures for staff development within Continuous Quality Improvement models. ${ }^{49}$ The translation of research evidence into policy and training, for example, on hospital admissions and tracking according to patient identity would help staff counter their possible implicit bias, with a view to fundamentally changing its orientation to more neutral over time. New approaches seeking reciprocal accountability between tertiary and primary health care settings, especially community-controlled Aboriginal health services ${ }^{49,50}$ and cultural safety audits of hospitals, ${ }^{51}$ offer real opportunities to recognize and address these iatrogenic effects.

\section{Conclusion}

This article identifies the iatrogenic effects of well-meaning initiatives in Aboriginal health within medical education and clinical settings. The authors are not arguing that the initiatives are wrong, but that awareness of the iatrogenic impacts is critical, if we are to consider the effects of our actions to ensure that the lives of Aboriginal people and communities are provided the opportunity to fulfill their full potential. In a society that is based on stratified and racialized power and that has operated such that the success of some is based on the oppression of others, we must be vigilant with regard to the unintended consequences of our good intent. The same attention paid to iatrogenic implications from complex drug interactions for an oncology patient needs to be paid to medically induced harm to Aboriginal health also, from current well-intentioned efforts in teaching and learning, and clinical care.

\section{Disclosure}

The authors report no conflicts of interest in this work.

\section{References}

1. Welfare AIoHa [homepage on the Internet]. AIHW Authoritative Information and Statistics to Promote Better Health and Wellbeing. 2016. Available from: http://www.aihw.gov.au/home/. Accessed February 20, 2016.

2. Cook DA. Narrowing the focus and broadening horizons: complementary roles for systematic and nonsystematic reviews. Adv Health Sci Educ Theory Pract. 2008;13(4):391-395.

3. Eva KW. On the limits of systematicity. Med Educ. 2008;42(9):852-853.
4. Beach MC, Price EG, Gary TL, et al. Cultural competency: a systematic review of health care provider educational interventions. Med Care. 2005;43(4):356-373.

5. Truong M, Paradies Y, Priest N. Interventions to improve cultural competency in healthcare: a systematic review of reviews. BMC Health Serv Res. 2014;14:99.

6. Haynes TM, Collins ME, Mazel O, Lawler LM, Ryan C, Ewen SC. History of the LIME network and the development of indigenous health in medical education. Med J Aust. 2013;199(1):65-68.

7. Mazel O, Ewen S. Innovation in indigenous health and medical education: the leaders in indigenous medical education (LIME) network as a community of practice. Teach Learn Med. 2015;27(3):314-328.

8. Colliver JA. Effectiveness of problem-based learning curricula: research and theory. Acad Med. 2000;75(3):259-266.

9. Shanley PF. Viewpoint: leaving the "empty glass" of problem-based learning behind: new assumptions and a revised model for case study in preclinical medical education. Acad Med. 2007;82(5):479-485.

10. Treloar C, McCall N, Rolfe I, Pearson SA, Garvey G, Heathcote A. Factors affecting progress of Australian and international students in a problem-based learning medical course. Med Educ. 2000;34(9):708-715.

11. Kai J, Bridgewater R, Spencer J. "'Just think of TB and Asians', that's all I ever hear": medical learners' views about training to work in an ethnically diverse society. Med Educ. 2001;35(3):250-256.

12. Prideaux D. Is valuing ethnic diversity enough? Should we expect ethnically and culturally safe practice? Med Educ. 1999;33(8):555-556.

13. Stoneham M, Goodman J, Daube M. The portrayal of indigenous health in selected Australian media. Int Indig Policy J. 2014;5(1):5.

14. Anderson IP, Ewen SC, Knoche DA. Indigenous medical workforce development: current status and future directions. Med J Aust. 2009;190(10):580-581.

15. Humphery K, Fitz J, Weeramanthri T. Forgetting Compliance. Darwin, NT: Northern Territory University Press; 2001.

16. Thomas D. Reading Doctors' Writing: Race, Politics and Power in Indigenous Health Research, 1870-1969. Acton, ACT: Aboriginal Studies Press; 2004.

17. Kowal E, Paradies Y. Ambivalent helpers and unhealthy choices: public health practitioners' narratives of indigenous ill-health. Soc Sci Med. 2005;60(6):1347-1357.

18. Powers BW, White AA, Oriol NE, Jain SH. Race-conscious professionalism and African American representation in academic medicine. Acad Med. Epub 2016 Jan 12.

19. Kinnane S, Wilks J, Wilson K, Hughes T, Thomas S. 'Can't Be What You Can't See': The Transition of Aboriginal and Torres Strait Islander Students into Higher Education, Final Report. Broome, WA: University of Notre Dame; 2014.

20. Ewen S, Barrett J, Howell-Meurs S. Health disparity and health professional education: a new approach. Med Sci Educ. 2016.

21. Ritz S. A Critical Discourse Analysis of Medical Students' Reflective Writing: Social Accountability, the Hidden Curriculum, and Critical Reflexivity. London, ON: University of Western Ontario; 2014.

22. Kelaher MA, Ferdinand AS, Paradies Y. Experiencing racism in health care: the mental health impacts for Victorian Aboriginal communities. Med J Aust. 2014;201(1):44-47.

23. Paradies Y, Cunningham J. Experiences of racism among urban indigenous Australians: findings from the DRUID study. Ethn Racial Stud. 2009;32(3):548-573.

24. Downing R, Kowal E. A postcolonial analysis of indigenous cultural awareness training for health workers. Health Sociol Rev. 2011;20(1):5-15.

25. Hollinsworth D. Unsettling Australian settler supremacy: combating resistance in university Aboriginal studies. Race Ethn Educ. 2016;19(2):412-432.

26. Kowal E, Franklin H, Paradies Y. Reflexive antiracism: a novel approach to diversity training. Ethnicities. 2013;13(3):316-337.

27. Ly A, Crowshoe L. 'Stereotypes are reality': addressing stereotyping in Canadian Aboriginal medical education. Med Educ. 2015;49(6): $612-622$. 
28. Haynes E, Taylor KP, Durey A, Bessarab D, Thompson SC. Examining the potential contribution of social theory to developing and supporting Australian indigenous-mainstream health service partnerships. Int J Equity Health. 2104;13(1):75.

29. Paul D, Ewen SC, Jones R. Cultural competence in medical education: aligning the formal, informal and hidden curricula. Adv Health Sci Educ Theory Pract. 2014;19(5):751-758.

30. Hafferty FW. Beyond curriculum reform: confronting medicine's hidden curriculum. Acad Med. 1998;73(4):403-407.

31. van Ryn M, Hardeman R, Phelan SM, et al. Medical school experiences associated with change in implicit racial bias among 3547 students: a medical student CHANGES study report. J Gen Intern Med. 2015;30(12):1748-1756.

32. Dobbin M. Heart of darkness: Melbourne University's racist professors. The Age. 2015 Nov 30.

33. Jones R [webpage on the Internet]. Eugenics in Australia: The Secret of Melbourne's Elite. The Conversation; 2011. Available from: http:// theconversation.com/eugenics-in-australia-the-secret-of-melbourneselite-3350. Accessed January 22, 2016.

34. Bradby H. Race, ethnicity and health: the costs and benefits of conceptualising racism and ethnicity. Soc Sci Med. 2012;75(6):955-958.

35. Varcoe C, Browne AJ, Wong S, Smye VL. Harms and benefits: collecting ethnicity data in a clinical context. Soc Sci Med. 2009;68(9):1659-1666.

36. Ewen SC, Barrett J, Paul D, Askew D, Webb G, Wilkin A. When a patient's ethnicity is declared, medical students' decision-making processes are affected. Intern Med J. 2015;45(8):805-812.

37. Nazione S, Silk KJ. Patient race and perceived illness responsibility: effects on provider helping and bias. Med Educ. 2013;47(8):780-789.

38. Teal CR, Gill AC, Green AR, Crandall S. Helping medical learners recognise and manage unconscious bias toward certain patient groups. Med Educ. 2012;46(1):80-88.

39. Woolf K, Dacre J. Reducing bias in decision making improves care and influences medical student education. Med Educ. 2011;45(8):762-764.

40. Cass A, Cunningham J, Snelling P, Wang Z, Hoy W. Exploring the pathways leading from disadvantage to end-stage renal disease for indigenous Australians. Soc Sci Med. 2004;58(4):767-785.

41. Cass A, Devitt J, Preece C, et al. Barriers to access by indigenous Australians to kidney transplantation: the IMPAKT study. Nephrology (Carlton). 2004;9(Suppl 4):S144-S146.
42. Davidson PM, Jiwa M, Digiacomo ML, et al. The experience of lung cancer in Aboriginal and Torres Strait Islander peoples and what it means for policy, service planning and delivery. Aust Health Rev. 2013;37(1): $70-78$.

43. Davidson PM, MacIsaac A, Cameron J, Jeremy R, Mahar L, Anderson I. Problems, solutions and actions: addressing barriers in acute hospital care for indigenous Australians and New Zealanders. Heart Lung Circ. 2012;21(10):639-643.

44. McBride K, Kelly J, Kite E, Keech W, Rischbieth A, Brown A. Experiences of Aboriginal and Torres Strait Islander people admitted for a cardiac event in Australian public hospitals: a systematic review protocol. JBI Database System Rev Implement Rep. 2014;12(9):45-57.

45. Anderson K, Devitt J, Cunningham J, Preece C, Jardine M, Cass A. If you can't comply with dialysis, how do you expect me to trust you with transplantation? Australian nephrologists' views on indigenous Australians' 'non-compliance' and their suitability for kidney transplantation. Int J Equity Health. 2012;11:21.

46. Mamede S, Schmidt HG, Penaforte JC. Effects of reflective practice on the accuracy of medical diagnoses. Med Educ. 2008;42(5):468-475.

47. Katzenellenbogen JM, Sanfilippo FM, Hobbs MS, et al. Voting with their feet: predictors of discharge against medical advice in Aboriginal and non-Aboriginal ischaemic heart disease inpatients in Western Australia, an analytic study using data linkage. BMC Health Serv Res. 2013;13:330.

48. Durey A, Thompson SC, Wood M. Time to bring down the twin towers in poor Aboriginal hospital care: addressing institutional racism and misunderstandings in communication. Intern Med J. 2012;42(1): 17-22.

49. Durey A, Wynaden D, Thompson SC, Davidson PM, Bessarab DC, Katzenellenbogen JM. Owning solutions: a collaborative model to improve quality in hospital care for Aboriginal Australians. Nurs Inq. 2012;19(2):144-152.

50. Dwyer J, Boulton A, Lavoie JG, Tenbensel T, Cumming J. Indigenous peoples' health care: new approaches to contracting and accountability at the public administration frontier. Public Manage Rev. 2014;16(8): 1091-1112.

51. Marrie A, Marrie H. A Matrix for Identifying, Measuring and Monitoring Institutional Racism within Public Hospitals and Health Services. Gordonvale, QLD: Bukal Consultancy services P/L; 2014.
Advances in Medical Education and Practice

\section{Publish your work in this journal}

Advances in Medical Education and Practice is an international, peerreviewed, open access journal that aims to present and publish research on Medical Education covering medical, dental, nursing and allied health care professional education. The journal covers undergraduate education, postgraduate training and continuing medical education

\section{Dovepress}

including emerging trends and innovative models linking education, research, and health care services. The manuscript management system is completely online and includes a very quick and fair peer-review system. Visit http://www.dovepress.com/testimonials.php to read real quotes from published authors. 